\title{
Fungos endofíticos isolados de ápices caulinares de pupunheira cultivada in vivo e in vitro
}

\author{
Cristina Vieira de Almeida ${ }^{(1)}$, Ricardo Yara $^{(2)}$ e Marcílio de Almeida(1)
}

\begin{abstract}
(1)Escola Superior de Agricultura "Luiz de Queiroz" (Esalq), Dep. de Ciências Biológicas, Caixa Postal 9, CEP 13418-900 Piracicaba, SP. E-mail: calmeida@esalq.usp.br, malmeida@esalq.usp.br (2)Esalq, Dep.de Genética. E-mail: ryara@esalq.usp.br
\end{abstract}

\begin{abstract}
Resumo - A perda de plantas micropropagadas ocorre, principalmente, pela presença de microrganismos, responsáveis pela morte das plantas no início da cultura ou em seu estabelecimento no campo. O trabalho teve como objetivo a identificação, por taxonomia clássica, e por meio de técnicas moleculares, de fungos presentes nos ápices caulinares de pupunheiras sadias, cultivadas no campo, e a comparação com os fungos isolados, em plantas micropropagadas há dois anos. Os isolados da microbiota fúngica endofítica, das plantas cultivadas in vitro, foram: Fusarium oxysporum, Neotyphodium sp. e Epicoccum nigrum; e das plantas in vivo, foram: Fusarium sp., F. proliferatum, F. oxysporum, Colletotrichum sp., Alternaria gaisen, Neotyphodium sp. e Epicoccum nigrum. As sete espécies de fungos foram reintroduzidas in vitro na planta hospedeira, demonstrando diferentes comportamentos. Neotyphodium sp. e E. nigrum estabeleceram uma interação endofítica com a planta, e as demais comportaram-se como patógenos, diminuindo o desenvolvimento das plântulas em relação às plantas sem inoculação. As espécies endofíticas apresentam potencial para o uso no controle biológico de patógenos de pupunha.
\end{abstract}

Termos para indexação: Bactris gasipaes, patógenos latentes, fungos, controle biológico.

\section{Endophytic fungi in shoot tip of the pejibaye cultivated in vivo and in vitro}

\begin{abstract}
Losses of micropropagated plants occur in its majority due to presence of microorganisms responsible for plant death both in culture beginning and plant establishment in field. Two years in vitro cultivated pejibaye shoot tips, showed the presence of fungi colonies after transference for new culture medium. This paper aimed at identifying fungi, by classical taxonomy and by molecular methods, present in shoot tip of healthy pejibaye plants, cultivated in the field, and to compare them with isolated ones of in vitro plants. The isolates of endophytic fungi community of the in vitro plants were Fusarium oxysporum, Neotyphodium sp. and Epicoccum nigrum; from the in vivo plants were Fusarium sp., F. proliferatum, F. oxysporum, Colletotrichum sp., Alternaria gaisen, Neotyphodium sp. and E. nigrum. The seven species of fungi were reinoculated in host plant, revealing different behaviour. Neotyphodium sp. and E. nigrum established an endophytic interaction with the host; the other fungi acted as pathogens causing decrease in seedlings development when compared to the non-inoculated plants. Species acting as endophytes present a potential use in biocontrol of pejibaye pathogens.
\end{abstract}

Index terms: Bactris gasipaes, latent pathogens, fungi, biological control.

\section{Introdução}

A pupunheira (Bactris gasipaes Kunth) é uma palmeira encontrada na costa Atlântica das Américas Central e do Sul, ao longo da costa do Pacífico (litoral da Colômbia e oeste do Equador), e ao sul da Costa Rica e norte do Peru (Clement \& Manshardt, 2000). Essa planta pode ser cultivada nas mais diversas condições climáticas, porém é notório que seu melhor desempenho ocorre em regiões de clima tropical quente e úmido (Deenik et al., 2000).
Em virtude da excelente qualidade do palmito, seu cultivo é cada vez mais freqüente, com plantios em escalas consideráveis no Pará, Acre, Rondônia e Mato Grosso. Essa cultura encontra-se em intenso processo de disseminação fora da Amazônia, principalmente no Sudeste, e está sendo plantada em praticamente todo o Estado de São Paulo. O cultivo ecologicamente correto da pupunheira contribui para a diminuição do consumo extrativista do palmito nativo (Euterpes edulis L.), extraído e industrializado de forma clandestina e ilegal. 
A obtenção de plantios uniformes dessa espécie pode ser feita por meio da micropropagação de matrizes selecionadas, como foi observado por Almeida \& Kerbauy (1996), que obtiveram excelentes resultados, a partir da reversão de botões florais em gemas vegetativas. A elevada ocorrência de contaminação, que pode ser verificada em culturas in vitro, restringe a realização de pesquisa nessa área com pupunheira, considerando tal fato como um agravante da técnica em questão. Observou-se, no entanto, que nem sempre tais contaminantes debilitavam as plantas micropropagadas, por isso seu isolamento e identificação dera origem a uma nova área de pesquisa, dentro da cultura de tecidos de pupunheira.

A interação e o isolamento desses microrganismos, além do controle das condições ambientais e da composição do meio de cultura, são extremamente facilitados em condições in vitro, em decorrência da produção maciça e velocidade de crescimento das plantas.

Contribuição importante na área de fitopatologia tem sido obtida a partir da aplicação de técnicas de cultura de tecidos (Helgeson \& Deverall, 1983). O sistema de co-cultura de patógenos e tecidos de plantas hospedeiras permite o estudo das relações entre os dois organismos, em condições controladas, e pode levar à descoberta de mecanismos de patogenicidade e de resistência em nível celular (Duval et al., 1998).

Na avaliação do comportamento de microrganismos endofíticos, Serafini et al. (2002) também destacam a importância da técnica de cultura in vitro, no estudo da relação entre microrganismos endofíticos e a planta micropropagada. Esses microrganismos foram definidos, por Hallmann et al. (1997), como aqueles que podem ser isolados do interior de tecidos vegetais desinfectados superficialmente, e que não causam danos ao hospedeiro. Essa definição inclui relações neutras e simbióticas.

Segundo Cutter (1986), o ápice caulinar é uma região sub-meristemática formada por células derivadas, que se encontram em constante divisão celular, e assim geram uma estreita faixa de células em diferenciação. Essa informação conduz à idéia de que se trata de uma região axênica ou, pelo menos, de pequena mobilidade para os microrganismos no vegetal.

O objetivo deste trabalho foi identificar a microbiota fúngica presente em ápices caulinares de pupunheiras adultas cultivadas in vivo, e compará-la com a observada em plantas micropropagadas.

\section{Material e Métodos}

Foram utilizadas pupunheiras, obtidas de matrizes adultas selecionadas no campo, fornecidas pelo Departamento de Produção Vegetal da Escola Superior de Agricultura “Luiz de Queiroz” (Esalq, Piracicaba).

As matrizes foram pulverizadas com fungicida Benomil (10\%), para o isolamento da microbiota fúngica endofítica das plantas desenvolvidas no campo. Após uma semana, os palmitos foram coletados e lavados em água corrente, com o auxílio de uma escova, removendo-se as impurezas aderidas à superfície. Em seguida, as bainhas foram retiradas para o isolamento dos ápices caulinares.

Os ápices foram lavados em água corrente por três horas, em frascos tampados com peneira de náilon de espessura média. Em seguida foram desinfestados com água sanitária (hipoclorito de sódio comercial, 30\% v/v) por meia hora, e enxaguados abundantemente com água destilada autoclavada. Os explantes foram depositados em placas de Petri contendo papel-filtro, e em seguida colocados em meio de cultura MS (Murashige \& Skoog, 1964); foram mantidos em sala de crescimento com temperatura e luminosidade controladas de $26 \pm 1^{\circ} \mathrm{C}$ e 16 h/luz (fluorescente 36 W/54, 6500 K; irradiância de $\left.15 \mathrm{mmol} \mathrm{m}^{-2} \mathrm{~s}^{-1}\right)$.

A purificação dos isolados foi feita por esgotamento, e seu cultivo se deu, em placas de Petri, com meio de cultura completo (Pontecorvo et al., 1953). Os isolados foram acondicionados em câmara de crescimento (BOD) a $28^{\circ} \mathrm{C}$, no escuro, e sua identificação foi feita por taxonomia clássica e por meio do seqüenciamento dos fragmentos da região de ITS (Internal Transcribed Spacer), segundo o método descrito por Raeder \& Broda (1985).

A microbiota fúngica endofítica, existente em plantas micropropagadas há dois anos, foi isolada à medida que os microrganismos surgiam, durante o processo de transferência para novos meios de cultura, ou seja, quando eles se tornavam visíveis, descartando-se todos os microrganismos que surgissem antes de 12 dias, após a transferência, para evitar possíveis contaminções.

Para avaliar a interação entre a microbiota associada à cultura no campo e às plantas micropropagadas, os isolados fúngicos, provenientes das duas condições de desenvolvimento das plantas (in vivo e in vitro), foram cultivados em meio de cultura BDA a $28^{\circ} \mathrm{C}$, por três dias. As suspensões de conídios foram preparadas em Tween $80(0,1 \%)$ e adicionadas ao meio de cultura MS, 
na concentração de $10^{3}$ conídios $\mathrm{mL}^{-1}$. Plantas micropropagadas selecionadas de acordo com o vigor, ou seja, plantas com a mesma altura, número de folhas e sistema radicular semelhantes, foram transferidas para esse meio de cultura. Após a reintrodução dos isolados, foi analisada a presença do fungo para saber se alterava o desenvolvimento das plantas.

\section{Resultados e Discussão}

Os ápices caulinares das plantas adultas cultivadas no campo, que foram colocados in vitro, apresentaram, num intervalo de 12 a 18 dias de cultivo, o desenvolvimento de colônias fúngicas. A classificação taxonômica clássica dos isolados permitiu a identificação no plano de gênero, e o seqüenciamento dos fragmentos de ITS possibilitou a identificação das seguintes espécies: Fusarium sp., F. oxysporum, F. proliferatum, Colletotrichum sp., Alternaria gaisen, Epicoccum nigrum e Neotyphodium sp.

Nas pupunheiras mantidas in vitro há dois anos, e portanto consideradas axênicas, surgiram colônias de fungos, durante o processo de repicagem e transferência para novos meios de cultura, que foram identificados como: E. nigrum, F. oxysporum e Neotyphodium sp. A presença de tais microrganismos, provavelmente, ocorre em conseqüência do estresse da planta, pelo empobrecimento nutricional e alteração do $\mathrm{pH}$ do meio de cultura, que antecede a transferência e gera uma redução na resistência da planta, que é aproveitada pelo fungo endofítico que se encontrava em condição de latência. Pereira et al. (2003) afirmam que quando as condições do meio de cultura (nutrição, $\mathrm{pH}$ ) se tornam favoráveis ao desenvolvimento, as bactérias passam a competir por nutrientes minerais e carboidratos, comprometendo a multiplicação e o desenvolvimento dos cultivos, o que pode levá-los rapidamente à morte.

De todos os isolados fúngicos que foram reintroduzidos em plantas in vitro, Fusarium sp., F. oxysporum, F. proliferatum, Colletotrichum sp. e A. gaisen causaram, após 10 dias, a morte das plantas por apodrecimento do sistema radicular ou tombamento da parte aérea, enquanto E. nigrum e Neotyphodium sp. mantiveram o desenvolvimento normal das plantas.

A atuação do Fusarium é bem estudada em plantas de campo, pois este é um fungo agressivo, responsável pela síndrome da queda dos frutos, assim como outras espécies, tais como: Ceratocystis paradoxa, Colletotrichum gloeosporioides, Cladosporium sp.,
Aspergillus sp., Verticillium sp., Penicillium sp., Alternaria alternata e Rhizopus sp. (Mota \& Gasparotto, 1998). Pizzinato et al. (2001) destacaram a morte de plantas de pupunha, em virtude da ocorrência de Fusarium spp., tanto em viveiro como em campo ou casa de vegetação, constatando a manifestação de sintomas aos sete e dez dias após a inoculação.

$O$ fungo do gênero Epicoccum é caracterizado como onívoro, por se encontrar em uma grande variedade de plantas, no solo, no ar, na pele humana e em insetos. São considerados saprofíticos, mas tornam-se parasitas sob determinadas circunstâncias. Dentre os trabalhos realizados com esse fungo, destacam-se o de Wittig et al. (1997), que observaram o controle da podridão parda do pessegueiro, com o uso de E. purpurascens em casa de vegetação; destaca-se, também o trabalho de Bhuiyan (2003), em que isolados de $E$. nigrum reduziram sensivelmente doenças fúngicas em sorgo. Cita-se, ainda, o trabalho realizado por Méndez \& Mondino (1999), com controle biológico em pós-colheita de frutos e hortaliças, em que E. nigrum foi utilizado em ensaios de antibiose com Sclerotinia sclerotiorum.

A presença dessa espécie de fungo em pupunheira pode ser de extrema importância, uma vez que essa cultura é consideravelmente prejudicada por microrganismos patogênicos, e em ensaios futuros, essa espécie poderá ser utilizada no controle biológico.

Os fungos endofíticos do gênero Neotyphodium, formalmente denominado Acremonium (Glenn et al., 1996), infectam espécies de gramíneas, muitas das quais são importantes forrageiras (Moy et al., 2002). Esses fungos colonizam os espaços intercelulares da parte aérea das plantas, e essa associação endófito-gramínea é geralmente considerada uma simbiose mutualística (Clay, 1988).

Em muitas dessas associações, a produção de alcalóides pelos fungos resulta na redução da herbivoria por insetos ou mamíferos, e isso beneficia a planta hospedeira e os fungos, que por sua vez se beneficiam pelo acesso aos nutrientes produzidos pela planta (Breen, 1994; Bush et al., 1997).

Neste trabalho foi possível observar que o gênero Neotyphodium sp., da mesma forma que o E. nigrum, não afetou o desenvolvimento das plantas micropropagadas. Esses fungos endofíticos, como o “fungus gnats", poderiam ser avaliados, no controle biológico de insetos em pupunheiras, como por exemplo no caso do inseto do gênero Bradysia, cujas larvas penetram nas plântulas e mudas, atingem a região do palmito e atuam de maneira semelhante ao Fusarium (Moro, 1996). 


\section{Conclusões}

1. A microbiota fúngica isolada de ápices caulinares de plantas adultas de pupunheira pode ser caracterizada como endofítica, pois as plantas não apresentam nenhum sintoma visual de patogenicidade.

2. Após a reintrodução dos isolados fúngicos em plantas axênicas, as espécies Fusarium sp., F. oxysporum, F. proliferatum, Colletotrichum sp. e Alternaria gaisen comportam-se como patogênicas.

3. Os fungos endofíticos E. nigrum e Neotyphodium sp. podem ser utilizados como agentes de controle biológico dos patógenos causadores do apodrecimento radicular de pupunheiras.

\section{Agradecimentos}

Ao Prof. Dr. Marcos S. Bernardes, do Dep. de Produção Vegetal da Esalq, pela doação das plantas de pupunha utilizadas neste trabalho; ao Prof. Dr. João Lúcio de Azevedo, por possibilitar o uso do Laboratório de Genética de Microrganismos da Esalq, para as avaliações moleculares; ao CNPq, pela concessão de bolsas de doutorado e recém-doutor.

\section{Referências}

ALMEIDA, M.; KERBAUY, G.B. Micropropagation of Bactris gasipaes H.B.K. (Palmae) through flower bud culture. Revista Brasileira de Fisiologia Vegetal, v.8, p.215-217, 1996.

BHUIYAN, S.A.; RYLEY, T.; GALEA, V.J.; TAY, D. Evaluation of potential biocontrol agents against Claviceps africana in vitro and in vivo. Plant Pathology, v.52, p.60-67, 2003.

BREEN, J.P. Acremonium-endophyte interactions with enhanced plant resistance to insects. Annual Review of Entomology, v.39, p.401-423, 1994.

BUSH, L.P.; WILKINSON, H.H.; SCHARDL, C.L. Bioprotective alkaloids of grass-fungal endophyte symbioses. Plant Physiology, v.114, p.1-7, 1997.

CLAY, K. Fungal endophytes of grasses: a defensive mutualism between plants and fungi. Ecology, v.69, p.10-16, 1988.

CLEMENT, C.R.; MANSHARDT, R.M. A review of the importance of spines for pejibaye heart-of-palm production. Scientia Horticulturae, v.83, p.11-23, 2000.

CUTTER, E.G. Anatomia vegetal: Parte 1- células e tecidos. 2.ed. Trad. Gabriela V.C.M. Catena. São Paulo: Roca, 1986. 304p.

DEENIK, J.; ARES, A.; YOST, R.S. Fertilization response and nutrient diagnosis in peach palm (Bactris gasipaes): a review. Nutrient Cycling in Agroecosystems, v.56, p.195-207, 2000.
DUVAL, C.M.; CALDAS, L.S.; RESENDE, R. de O. Aplicações da cultura de tecidos na fitopatologia. In: TORRES, A.C.; CALDAS, L.S.; BUSO, J.A. (Ed.). Cultura de tecidos e transformação genética de plantas. Brasília: Embrapa-SPI, 1998. p.45-68.

GLENN, A.E.; BACON, C.W.; PRICE, R.; HANLIN, R.T. Molecular phylogeny of Acremonium and its taxonomic implications. Mycologia, v.88, p.369-383, 1996.

HALLMAN, J.A.; QUADT-HALMANN, W.; MAHAFFEE, F.; KLOEPPER, J.W. Bacterial endophytes in agricultural crops. Canadian Journal of Microbiology, v.43, p.895-914, 1997.

HELGESON, J.P.; DEVERALL, B.J. (Ed.). Use of tissue culture and protoplasts in plant pathology. New York: Academic Press, 1983. 194p.

MENDEZ, S.V.; MONDINO, P. Control biológico postcosecha en Uruguay. Horticultura Internacional, v.7, p.29-36, 1999.

MORO, J.R. Produção de palmito de pupunha: manual. Viçosa: CPT, 1996. 28p. (CPT. Agricultura, manual, 87).

MOTA, A.M. da; GASPAROTTO, L. Fungos associados à "síndrome da queda de frutos" da pupunheira. Revista da Universidade do Amazonas: Série Ciências Agrárias, v.7, p.69-79. 1998.

MOY, M.; LI, H.M.; SULLIVAN, R.; WHITE JUNIOR, J.F.; BELANGER, F.C. Endophytic Fungal $\beta$-1,6-Glucanase expression in the infected host grass. Plant Physiology, v.130, p.1298-1308, 2002.

MURASHIGE, T.; SKOOG, F. A revised medium for rapid growth and bioassay with tobacco tissue cultures. Plant Physiology, v.15, p.473-497, 1964.

PEREIRA, J.E.S.; MATTOS, M.L.T.; FORTES, G.L.R. Identificação e controle com antibióticos de bactérias endofíticas contaminantes em explantes de batata micropropagados. Pesquisa Agropecuária Brasileira, v.38, p.827-834, 2003.

PIZZINATTO, M.A.; BOVI, M.L.A.; SPIERING, S.H.; BINOTTI, C.S. Patogenicidade de cinco espécies de Fusarium a plantas de pupunheira (Bactris gasipaes). Summa Phytopathologica, v.27, p.272-275, 2001.

PONTECORVO, G.; ROPER, J.A.; HEMMONS, L.M.; MacDONALD, K.D.; BUFTON, A.W.J. The genetics of Aspergillus nidulans. Advances in Genetics, v.5, p.141-238, 1953.

RAEDER, U.; BRODA, P. Rapid preparation of DNA from filamentous fungi. Letters in Applied Microbiology, v.1, p.17-20, 1985.

SERAFINI, L.A.; BARROS, N.M.; AZEVEDO, J.L. de. Biotecnologia: avanços na agricultura e na agroindústria. Caxias do Sul: Educs, 2002. 433p.

WITTIG, H.P.P.; JOHNSON, K.B.; PSCHEIDT, J.W. Effect of epiphytic fungi on brown rot blossom blight and latent infections in sweet cherry. Plant Disease, v.81, p.383-387, 1997. 